\title{
Beyond Placebo
}

\section{Maja Roje-Novak*}

Department of Neurology, Private Clinic, Croatia

*Corresponding Author: Maja Roje-Novak, Department of Neurology, Private Clinic, Croatia.
Received: March 04, 2021

Published: March 24, 2021

(C) All rights are reserved by Maja

Roje-Novak.
Placebo reaction is a relief of symptoms based on using medically inactive substances or procedures. It seems that a human brain has innate capability of restituting wellbeing according to motivation to regain health and preserve one's life. Brain- mind responds to informational context around the placebo treatment rather than the substance itself. Rituals around healing procedures stimulates human mind and this stimulation activates cascade of neurochemical processes which involve opioids and dopamine. Activated prefrontal cortex elicits reactions in neurovegetative system and hormonal axis which are both connected to immunity and other bodily functions.

Rituals around placebo reactions are not necessarily of alternative medicine nature. Even classical medical procedures seen in biomedicine like white coat of a doctor, pills, injections etc., can represent placebo rituals.

So, placebo reaction is a part of every medical or just perceived medical procedures and can contribute to re-establishing health. Placebo reactors are individuals who:

- Has predisposition to be cured

- Has motivation for regaining health

- Are- approaching medical service

- $\quad$ Are in- agreement to be in a medical procedure.

Experience empowerment thru ritual that which provide direct experience of being contacted with culturally recognized healing influences.

According to Rappaport theory of ritual, all healing rituals have to consists of the following:

- Evocation of space time and words separate from the ordinary (conversation with an omnipresent power full being that can make a change)
- $\quad$ Enactment (performance) that grabs patient attention with multisensory evidence of being enveloped with a universal omnipotent force (reciting the text which is emotionally charged)

- Concrete embodiment of a potent force healing influences are being directly ingested, injected, absorbed or incorporated. This rite is tangible, immediate and physically experienced (holding the cross or the rosary, drinking wine- blood of Jesus etc)

- An opportunity of evaluation of a new status.

An outcome being positive or negative or a combination of those is generally explainable within pre-existing cultural preconceptions of how healing should take place. If dissatisfied with the outcome patients have other options ad healers will have POST HOC rationalisations and if sufficiently charismatic will have new opportunities for fine tuning with other skills.

If therapy succeeds a patient will have a concrete perception of transformation in a form of "impeachable experience".

\section{Prayer as a placebo}

Prayer can be considered as a placebo because it complies with defined elements of a ritual theory.

According to Rappaport s model of a ritual, all healing rituals have to consist of the following: evocation of space time and words separate from the ordinary.

Prayer is a conversation with a omnipresent power full being that can make a change.

Enactment (performance) that grabs patient attention with multisensory evidence of being enveloped with a universal force: reciting the text which is emotionally charged. 


\section{Example}

Father in the name of Jesus of Nazareth, I thank you for the finished work of the cross. I declare i am more than a conqueror thru the One that loves me unconditionally... etc.

Concrete embodiment of a potent force healing influences are being directly ingested, injected, absorbed or incorporated. This rite is tangible, immediate and physically experienced.

Holding the cross or the rosary, drinking wine- blood of Jesus etc.

An opportunity of evaluation of a new status. if not cured go to the step one which is.. you have to believe more...

Synchronicity as the occurrence of two parallel events that are connected by meaning and not by cause is described as occurrence that accompanies the regular mode of prayer.

This phenomenon has been described in only two scientific originals, namely by Temple (1990) and Dr. Maja roje Novak (2019).

Synchronicity as a phenomenon has been described by $\mathrm{dr} C$ G Jung as a phenomenon that cannot be explained by the laws of statistics, biased reasoning, or apophenia. Jung believed that synchronicity is being favored a by subconscious meditative state.

Contemporary researchers on the phenomenon of synchronicity American authors Robert Perry and Gerry Schwartz, have divided synchronicities into subgroups:

- $\quad$ Such as paying attention to the phenomenon itself-i.e. you think about a red car and suddenly a red car is crossing the street

- You think of a song and suddenly your friend is telling you something about this song

- Synchronicity as a parabolic answer to a personal question or a solution to a situation

- You need an information and accidentally it pops out on the internet without searching.

You think about quitting a job and your friend calls you telling about the risks of being self employed etc.

Since two phenomena connected in synchronicity are not connected by a cause and effect but by meaning we can conclude they are connected nonlocally.
We can further conclude that those phenomena transcend personal action, thus we name them: transpersonal.

Further on, synchronicities can lead us to establish the principle of similarity or symmetry and holographic universe. One situation attracting like situation- what is like, unto itself is drawn.

In popular literature this is a notorious law of attraction.

In medicine this phenomenon can be maybe used for medical healing.

If we make a mental picture or simulate situations (as if) we are cured, the principle of similarity will come into play and draw in our reality a wanted outcome. (Visualisation, drawing of a map etc.).

If we connect this process with prayer, it will be more likely that we can attract wanted similarity into our life.

So, prayer can attract healing by promoting synchronicities and we can conclude that prayer doesn't work just by a placebo reaction but also in a transpersonal non-local way by facilitating convenient synchronicities.

\section{Assets from publication with us}

- Prompt Acknowledgement after receiving the article

- Thorough Double blinded peer review

- Rapid Publication

- Issue of Publication Certificate

- High visibility of your Published work

Website: $\underline{w w w}$.actascientific.com/

Submit Article: www.actascientific.com/submission.php Email us: editor@actascientific.com

Contact us: +919182824667 